\title{
Aिए \\ Antimony Influence on Shape of Eutectic Silicium in Al-Si Based Alloys
}

\author{
D. Bolibruchová *, M. Brůna \\ Department of Technological Engineering, University of Zilina, Univerzitna 1, 01026 Zilina, Slovakia \\ *Corresponding author. E-mail address: danka.bolibruchova@fstroj.uniza.sk
}

Received 30.03.2017; accepted in revised form 15.06.2017

\begin{abstract}
Liquid AI-Si alloys are usually given special treatments before they are cast to obtain finer or modified matrix and eutectic structures, leading to improved properties. For many years, sodium additions to hypoeutectic and eutectic AI-Si melts have been recognized as the most effective method of modifying the eutectic morphology, although most of the group IA or IIA elements have significant effects on the eutectic structure. Unfortunately, many of these approaches also have associated several founding difficulties, such as fading, forming dross in presence of certain alloying elements, reduced fluidity, etc. In recent years, antimony additions to AI-Si castings have attracted considerable attention as an alternative method of refining the eutectic structure. Such additions eliminate many of the difficulties listed above and provide permanent (i.e. non-fading) refining ability. In this paper, the authors summarize work on antimony treatment of Al-Si based alloys.
\end{abstract}

Keywords: Antimony, Modification, Aluminium

\section{Introduction}

The market with aluminum alloys castings is still one of the biggest in the casting industry. That is because of permanent requests for high quality and light castings, mainly in automotive and aerospace industry. The alloys based on Al-Si are one of the most used material in foundry due to their good casting and mechanical properties.

Considerable improvement of Al-Si alloys mechanical properties is already good known and analysed. From experiments results that the fibrous shape of modified aluminium - silicium eutectic can be achieved by rapid cooling or modification. Modification can be achieved by small amount of certain elements addition and presents simple and comfortable method to achieve optimal mechanical properties. Some elements from the IA and IIA group of periodical system can be used for modification, especially strontium, natrium and antimony are of large importance. [1,2]

\section{Modification with antimony}

Hypoeutectic $\mathrm{Al}$ - Si alloys modified with antimony have excellent casting properties, better that can be achieved by natrium and strontium. The antimony addition causes to rise an eutecticum area in hypoeutectic alloys and decrease area of silicium in eutectic. Only minimal influence on tensile strength is observed after antimony addition up to $4 \mathrm{wt}$. \%, while next addition, especially at hypoeutectic alloys, shows quite negative effect.

AlSb compound should serve as effective "nucleus creator" for eutectic silicium phases. Antimony added into melt oxidizes with the minimum extent and it is time-stable. Al-Si alloys modification with antimony shows insignificant sensibility for gases absorption. Antimony modification is effective only at high cooling rate. Hereby the utilization of antimony is limited only for die casting. $[3,4]$ 


\section{Experiment}

For experimental tests was used material AlSi7Mg0.3, its chemical composition is introduced in the table 1. It features good mechanical properties, excellent resistance to corrosion and good cast properties. This alloy is heat treated.

Table 1 .

Chemical composition of used alloy

\begin{tabular}{lcccccc}
\hline Element & Si & Mg & Cr & Mn & Cu & Ti \\
\hline (wt. \%) & 7.01 & 0.308 & 0.0007 & 0.018 & 0.001 & 0.122 \\
\hline
\end{tabular}

The modificator AlSb was used for experimental tests. All experimental casts were executed in the casting laboratory Department of technological engineering. Each casts differed by amount of used modificator AlSb. Realized casts consist of three samples with circular section $\varnothing 18 \times 155 \mathrm{~mm}$.

The choice of modificator amount is based on literary research, where recommended amounts differed from $50 \mathrm{ppm}$ to $10,000 \mathrm{ppm}$. Melt treatment consisted of graduated modification with AlSb modificator and melt purifying. Amount of batch material used in each casts are mentioned in the table 2. Individual casts were purified with purifying salt Dursalit LK $59 / 2$ before casting.

Casting of melt metal was executed into metal mold. The temperature of metal mold was $150^{\circ} \mathrm{C}$, casting temperature $730^{\circ} \mathrm{C}$.

Table 2.

Modificator amount used in casts

\begin{tabular}{cccccc}
\hline Cast no. & 1 & 2 & 3 & 4 & 5 \\
\hline $\begin{array}{c}\text { AlSb10 } \\
\text { [ppm] }\end{array}$ & - & 10000 & 50 & 70 & 90 \\
\hline Cast no. & 6 & 7 & 8 & 9 & 10 \\
\hline $\begin{array}{c}\text { AlSb10 } \\
\text { [ppm] }\end{array}$ & 110 & 130 & 160 & 500 & 1000 \\
\hline
\end{tabular}

Antimony influences eutectic silicium by different process as the natrium or strontium does. Antimony addition does not create fibrous morphology of silicium phase, but lamellar, which is between acicular and fibrous shape. Lamellar shape of eutectic silicium occurs in Al-Si alloys hypomodified with natrium and strontium. A lot of researchers published, that lamellar shape of eutectic silicium causes the decreasing of mechanical characteristics. Antimony is affecting the most in interaction with rapid cooling rates.

By comparison of microstructures (Fig. 1a to 6a) there is no visible changes of eutectic silicium shape. The method of deep etching was used for the study of eutectic silicium morphology (i.e. arrangement of non-soluble phases). Evaluation of phases morphology (eutectic silicium) provides fundamental knowledge about real achieved structure. Deep etching has showed that the crystals of non-modified silicium are platy, facetted, hexagonal shapes. Large importance for continual growth of eutectic silicium has so-called branching of $\mathrm{Si}$ crystals plates. Modificators cause discontinual growth of Si by initiation of new facettes production. It is visible due to the change of lamellar eutectic into acicular. Eutectic Si crystals have so-called tufted distribution. In case of microstructure on Fig. $1 \mathrm{~b}$ there is the distribution of eutectic silicium plates fanwise, on Fig. $2 b$ fanwise fractional. Deep etching on Fig. 3b suggests combination of both past cases occurred, what is the cause of low modificator amount; i. e. alloy is hypomodified.

Microstructure of non-modified alloy is mentioned on the Fig. $1 \mathrm{a}$ and $\mathrm{b}$. Structure is created by the dendrites of $\alpha$ - phase and mixed structure containing areas with acicular and lamellar silicium. Such structure is not typical for non-modified alloy $\mathrm{AlSi} 7 \mathrm{Mg} 0.3$. In this case primary alloy contains increased volume of strontium (0.0213 wt. \%), i. e. the alloy is hypomodified.

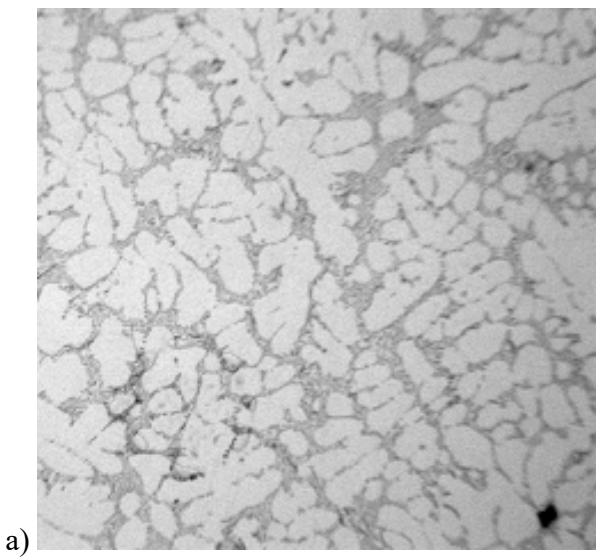

b)



Fig. 1. Microstructure of not by us modified AlSi7Mg0.3 alloy,

a) etch. $0.5 \% \mathrm{HF}, 100 \mathrm{x}, \mathrm{b})$ deep etching, $1500 \mathrm{x}$

On the Fig. 2a and b is showed alloy's microstructure modified with $50 \mathrm{ppm}$ AlSb10. Structure is created with dendrites of $\alpha$-phase and mostly coarsed silicium plates typical for nonmodified structure, but these shapes are finer than $\alpha$-phase because of modification effect of AlSb10. With this amount of AlSb10 has occurred the elimination of modification effect of strontium contained in primary alloy, their effects eliminate each other. 
a)
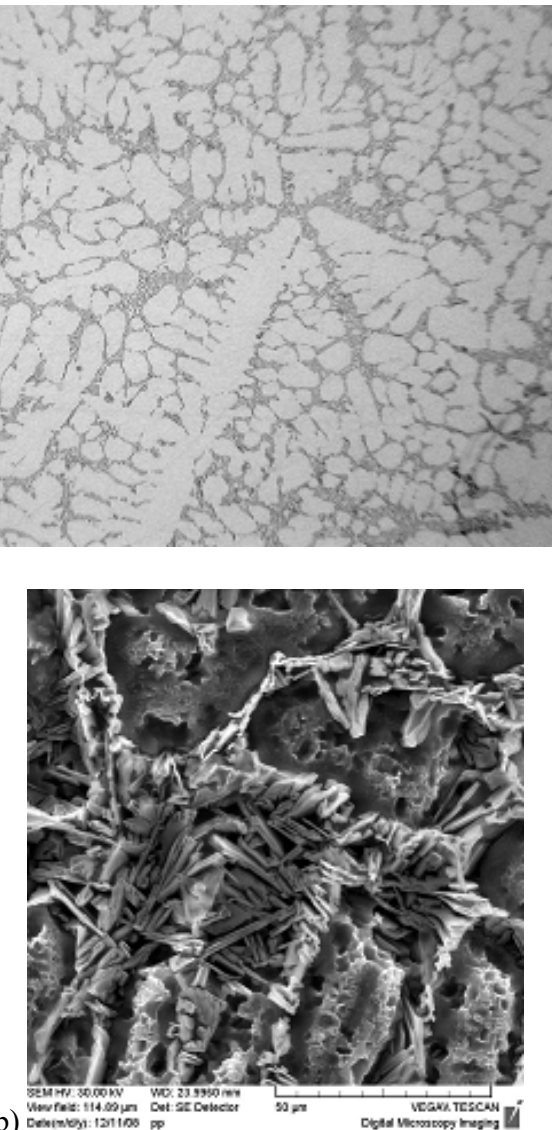

b)

Fig. 2. Microstructure of alloy modified with $50 \mathrm{ppm}$ AlSb10:

a) etch. $0.5 \% \mathrm{HF}, 100 \mathrm{x}, \mathrm{b})$ deep etching, 1500x

The microstructure is composed of $\alpha$ - phase dendrites and modified eutectic when used modificator with amount of 70 to $160 \mathrm{ppm}$. Silicium is excluded in the shape of fine and coarsed plates. The fraction of fine plate silicium formation is increasing with increasing amount of modificator.

a)

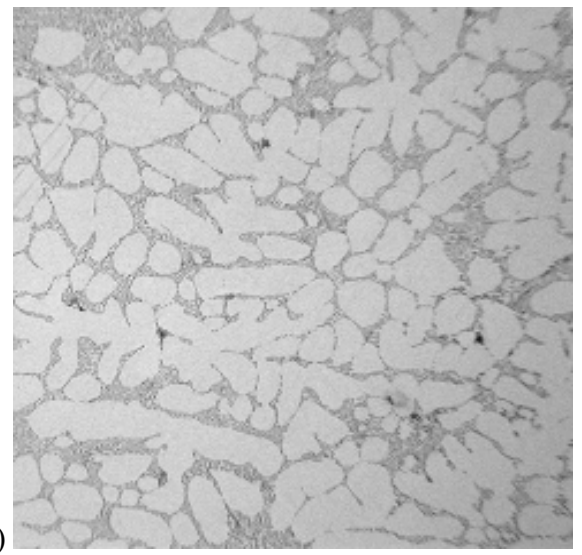

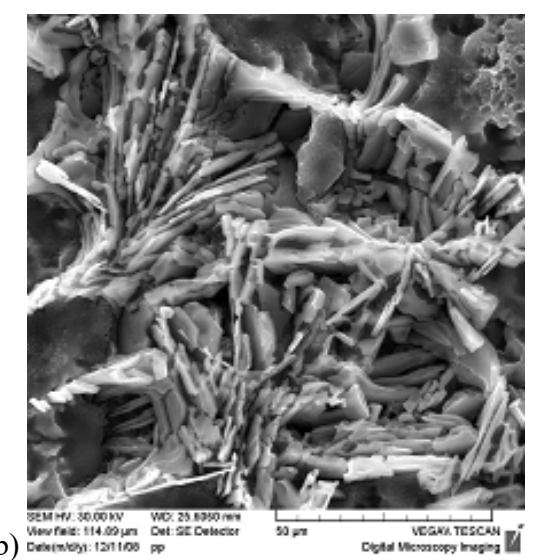

Fig. 3. Microstructure of alloy modified with 90 ppm AlSb10: a) etch. $0.5 \% \mathrm{HF}, 100 \mathrm{x}, \mathrm{b})$ deep etching, $1500 \mathrm{x}$

On the Figures $4 a$ and $b$ is shown microstructure of alloy modified with $500 \mathrm{ppm}$ AlSB10. Structure is created with dendrites of $\alpha$ - phase and lamellar eutectic. Silicium is excluded in the shape of thin lamellas typical for lamellar eutectic.
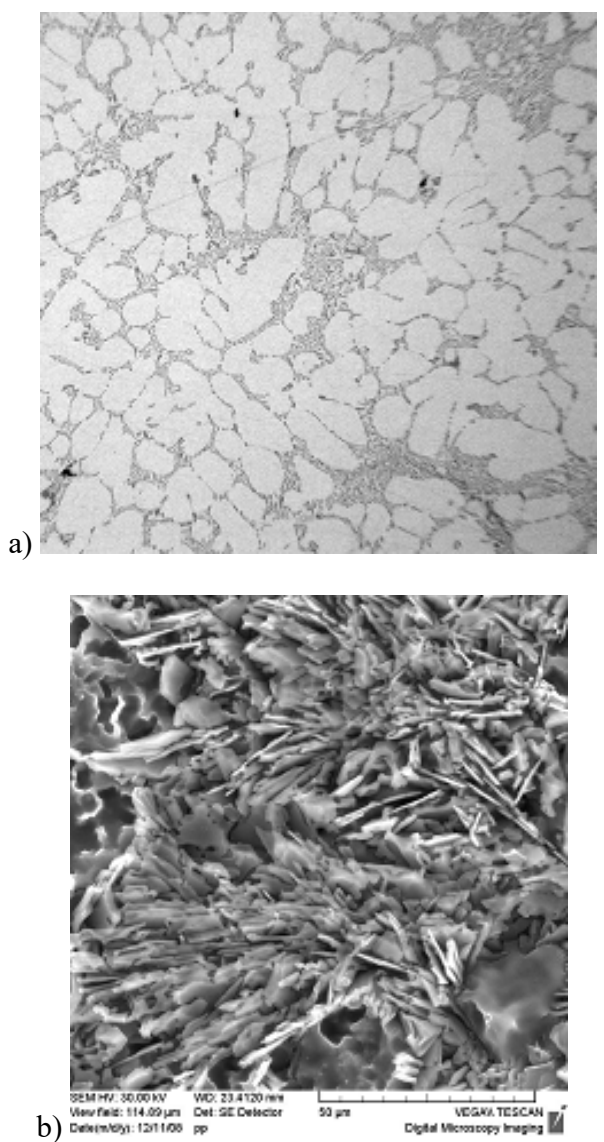

Fig. 4. Microstructure of alloy modified with 500 ppm AlSb10:

a) etch. $0.5 \% \mathrm{HF}, 100 \mathrm{x}, \mathrm{b}$ ) deep etching, $1500 \mathrm{x}$

On the Figures $5 \mathrm{a}$ and $\mathrm{b}$ there is also the microstructure with typical lamellar morphology of silicium. Structure is created with dendrites of $\alpha$ - phase and lamellar eutectic. 
a)

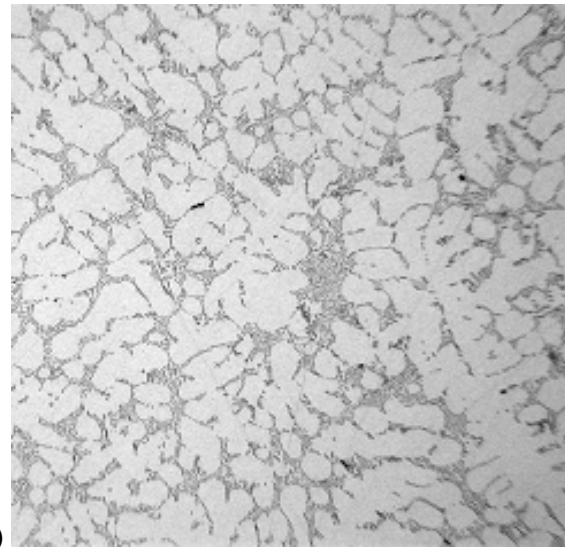

b)

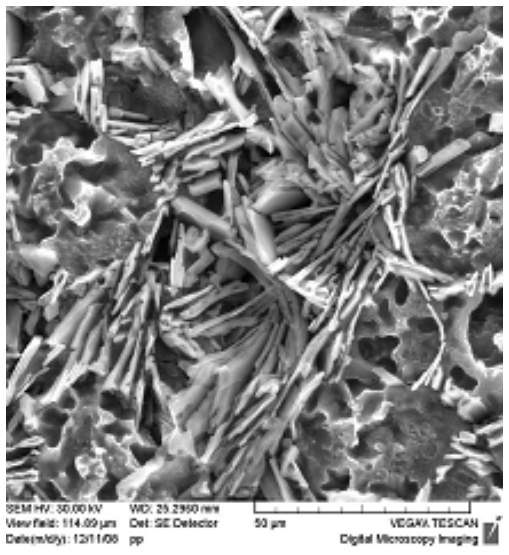

Fig. 5. Microstructure of alloy modified with $1000 \mathrm{ppm}$ AlSb10:

a) etch. $0.5 \% \mathrm{HF}, 100 \mathrm{x}, \mathrm{b}$ ) deep etching, $1500 \mathrm{x}$

On the Figures $6 \mathrm{a}$ and $\mathrm{b}$ there is the microstructure of alloy with 10,000 ppm AlSb10. Morphology of excluded silicium is typical for overmodified eutectic.

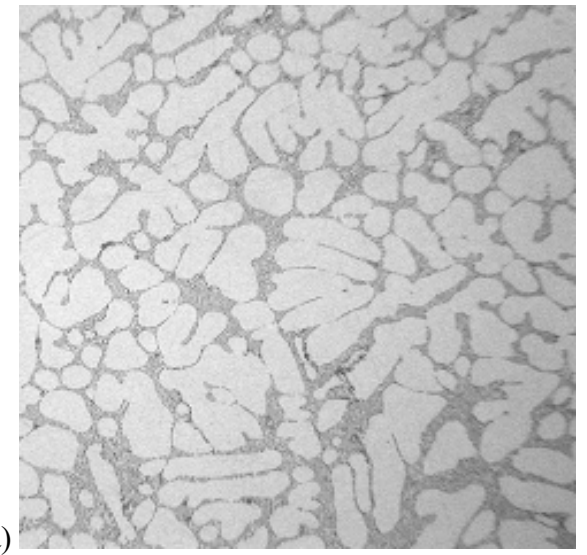

b)

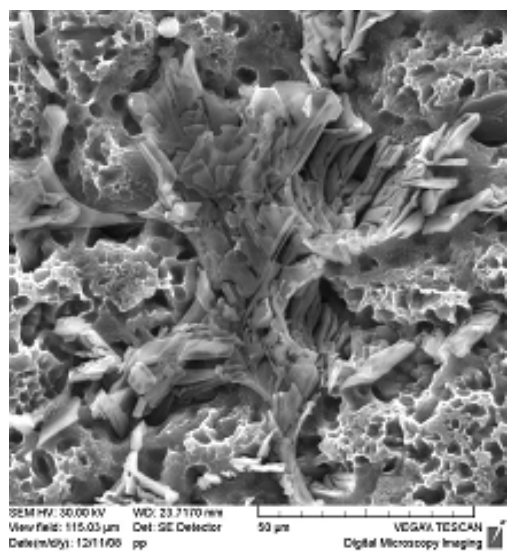

Fig. 6. Microstructure of alloy modified with 10,000 ppm AlSb10: a) etch. $0.5 \% \mathrm{HF}, 100 \mathrm{x}, \mathrm{b}$ ) deep etching, $1500 \mathrm{x}$

\section{Conclusions}

By the modification of AlSi7Mg0.3 alloy with graduated amount of AlSb10 modificator casted into metal mould was determined, in spite of practically identical Figures of microstructure (Fig. 1a to 6a) there comes to morphology change of eutectic silicium after antimony modification. Antimony as modificator for Al-Si alloys create prior conditions for formation of lamellar eutecticum compared with acicular eutectic after usage of strontium or natrium. Best mechanical characteristics from observed experiments set were achieved at usage of 500 and $1,000 \mathrm{ppm}$ AlSb10. Due to the modification effects of antimony with this amount, finer and partly curved needles silicon were formed which have a positive effect on the properties of the material.

\section{References}

[1] Bolibruchová, D., Tillová, E. (2005). Casting alloys Al-Si. 1 edition EDIS - Žilina, Slovakia.

[2] Krivoš, E., Pastirčák, R. \& Madaj, (2014). Effect of technological parameters on the quality and dimensional accuracy of castings manufactured by patternless process technology. Archives of Metallurgy and Materials. 59(3), 1069-1072. ISSN 1733-3490.

[3] Pastirčák, R., Ščury, J. (2016). Effect of technological parameters on microstructure in alloy AlCu4Ti using squeeze casting. In American Institute of Physics Publising. ISSN 0094-243X, 2016, AIP conference proceedings, vol. 1745.

[4] Tillová, E., Chalupová, M., Hurtalová, L., Durníková, E. (2011). Quality control of microstructure in recycled Al-Si cast alloys. Manufacturing Technology, 11(11), 70-76. 